\title{
Management of Incomplete Abortions by the Manual Intra Uterine Suction Technique at Sylvanus Olympio Teaching Hospital of Lome-Togo
}

Ameyo Ayoko Ketevi ${ }^{1 *}$, Baguilane Douaguibe ${ }^{1}$, Akila Bassowa ${ }^{2}$, Dede Regine Diane Ajavon ${ }^{3}$, Assiaham Walawita Tenete $^{1}$, Samira AYAB A ${ }^{1}$, Nagbe Massogblé Kodjo Koffi ${ }^{1}$, Kodjo Fiagnon ${ }^{1}$, Abdoul-Samadou Aboubakari ${ }^{4}$

\author{
${ }^{1}$ Department of Gynecology and Obstetrics, Sylvanus Olympio Teaching Hospital, Lome, Togo \\ ${ }^{2}$ Department of Gynecology and Obstetrics, Campus Teaching Hospital, Lome, Togo \\ ${ }^{3}$ Department of Gynecology and Obstetrics, Regional Hospital center, Kara, Togo \\ ${ }^{4}$ Department of Gynecology and Obstetrics, Kara Teaching Hospital, Kara, Togo
}

DOI: $10.36348 /$ sijog.2020.v03i11.001

| Received: 31.10 .2020 | Accepted: 13.11.2020 | Published: 23.11 .2020

*Corresponding author: Améyo Ayoko Ketevi

\section{Abstract}

Objective: to assess the management of incomplete abortions using the manual intrauterine aspiration technique (MIUA) in the Obstetric Gynecology clinic of the SO CHU. Method: This is a retrospective, descriptive study that took place at the gynecology and obstetrics clinic of the SO University of Lomé, over a period of 12 months (January to December 2017). Results: Of the 7440 pregnancies recorded, there were 460 abortions, $(6.18 \%)$. Among the abortions, there were 126 cases of incomplete abortions managed by the MIUA, a frequency of $27.39 \%$. The average age was 27 years with extremes of 13 and 54 years. Local anesthesia coupled with verbacaine has been used in all of our patients. The use of analgesics by injection before and after aspiration was systematic. Red blood cells were prescribed in $13.5 \%$ of cases, fresh frozen plasma in $4.8 \%$ of cases and antianemics in $90.48 \%$ of cases. All of our women (100\%) had fluids, antibiotics, analgesics and syntocinon. In $64.29 \%$, our patients had not adopted a contraceptive method after counseling. In contrast, $22.22 \%$ of them opted for the pills. Conclusion: Abortions, whether spontaneous or induced, constitute a public health problem and therefore require adequate management. The availability and simplicity of the MIUA technique are definite advantages.

Keywords: Abortion, manual intrauterine aspiration, Togo.

Copyright $\odot 2020$ The Author(s): This is an open-access article distributed under the terms of the Creative Commons Attribution 4.0 International License (CC BY-NC 4.0) which permits unrestricted use, distribution, and reproduction in any medium for non-commercial use provided the original author and source are credited.

\section{INTRODUCTION}

Manual vacuum aspiration (MVA) is one of the generally recommended surgical methods up to 12 to 14 weeks gestation [1]. Widely used, they are included in postabortion care programs, to manage complications or incomplete abortions [2, 3]. Unsafe abortion is a global health challenge that kills approximately 47,000 women each year [4] and causes serious sequelae in five million more women [5]. We also note that cases of spontaneous and induced abortions present in health establishments as cases of spontaneous miscarriages for post-abortion care [6, 7]. The West African region is most affected by this problem. The World Health Organization (WHO) estimates that more than 1.8 million unsafe abortions are performed each year in West Africa, with a death rate of 540 per 100,000 abortions, which represents by far the highest rate in the world.

In French-speaking West Africa, efforts have primarily been focused on postabortion care (PAC), a strategy that involves treating complications from incomplete and unsafe abortions already underway [5]. Gradually, the use of manual or electric vacuum suction has been widely recommended to replace dilation and curettage for a gestational age of less than 13 weeks. Indeed, vacuum aspiration presents fewer complications than metal curettage and can be performed by mid-level health workers [8-10]. In Togo, in 2012, the number of abortions registered in maternal health services was estimated at 6,976 [11]. 
Postabortion care (PAC) was introduced in Togo in 2006 [5]. The comprehensive woman-centered abortion care model of care as designed by Ipas includes, induced and safe abortion (or voluntary termination of pregnancy - abortion); treatment of incomplete, missed or unsafe abortion (or PAC) [5].

The general objective of our study is to evaluate the management of incomplete abortions by the manual intrauterine aspiration technique in the Obstetrics Gynecology clinic of The Sylvanus Olympio Teaching Hospital of Lome.

\section{METHODOLOGY}

This is a retrospective, descriptive study that took place at the gynecology and obstetrics clinic of the SO University of Lomé, from January to December 2017 (12 months). All patients carrying a pregnancy whose gestational age is less than or equal to $14 \mathrm{WA}$ having benefited from management by MVA and who were admitted for bleeding or provided with an ultrasound confirming an incomplete abortion of normal pregnancy, molar or clear egg were included. The data was collected from the medical records of the patients. A questionnaire made up of different variables was developed,

The data were processed with Excel software, the word processing was done on Microsoft Office Word 2010. For deontological and ethical reasons, an authorization ref 27/2018 / CHU / DIR / TG was obtained and the anonymity was maintained. The operational definitions of concepts used in this study were:

1. The type of abortion: was considered an induced abortion, any abortion mentioned in this sense in the clinical records; and as spontaneous abortion when no mention was made or specified this type of abortion.

2. Gestational age at the time of the abortion: was estimated in SA from the date of the last menstrual period or on ultrasound.

3. Evacuation procedure: The technique used to ensure uterine evacuation is MVA.

4. Pain control procedures: Verbacaine (verbal anesthesia); Local anesthesia;

5. Pain: abnormal and painful impression received by a living part and perceived by the brain, it can be: Minimal therefore unimportant; Moderate therefore mixed; Extreme therefore felt in the highest degree.

6. Counseling: all the information and information provided to patients during treatment.

7. Quality of care: the degree to which the care provided to the patient increases the probability of desired results and decreases those of unintended results.

8. Effectiveness: complete evacuation

\section{RESULTS \\ Frequency}

Of the 7,440 registered pregnancies, there were 460 abortions, a frequency of $6.18 \%$. Among the abortions, there were 126 cases of incomplete abortions managed by the MIUA, a frequency of $27.39 \%$ (126/460). Spontaneous abortions accounted for $61 \%$. Induced abortions, $39 \%$.

\section{Socio-demographic characteristics of patients Age}

The 20-25 age group was the most represented with a frequency of $29 \%$. The average age was 27 years with extremes of 13 and 54 years (Figure-1).

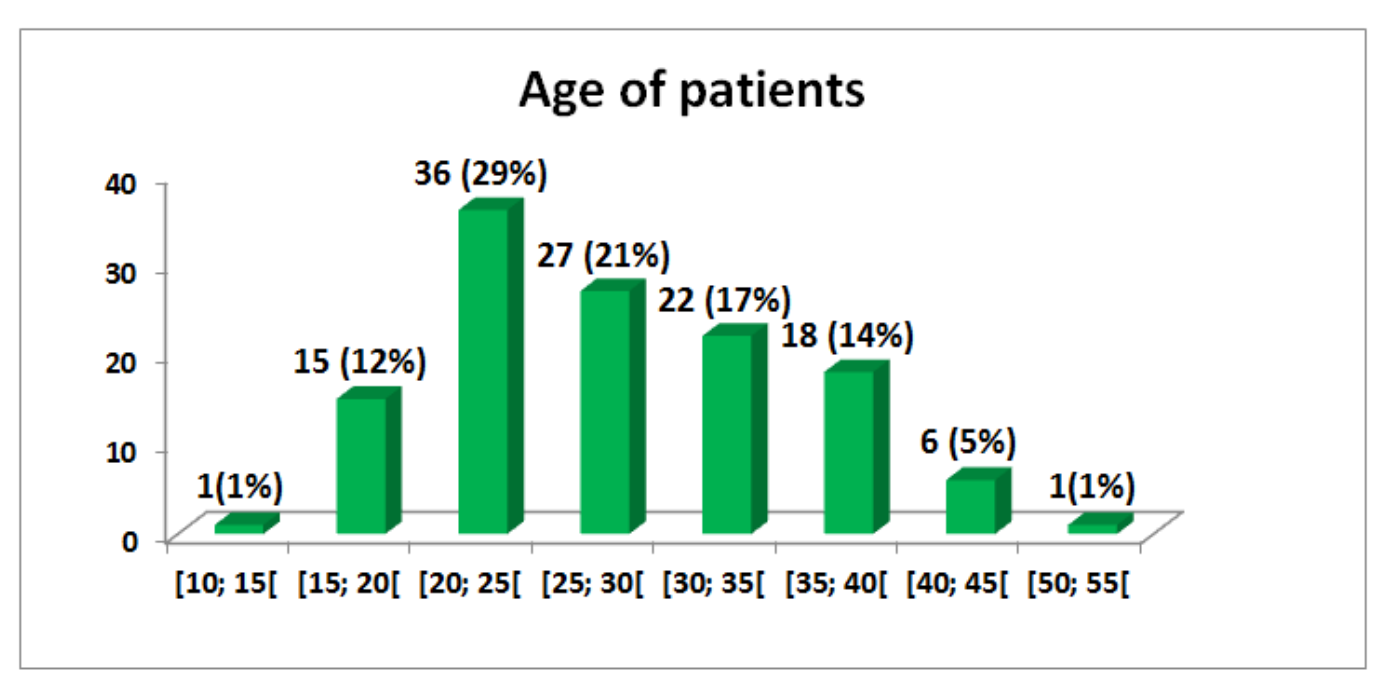

Fig-1: Distribution of patients by age 


\section{Profession and type of abortion}

Induced abortion was the prerogative of pupils and students $77.78 \%$ while spontaneous abortion that of patient civil servants $87.5 \%$ (Table-1).

Table-1: Type of abortion in relation to the profession

\begin{tabular}{|l|l|l|l|l|l|}
\hline & $\begin{array}{l}\text { Pupil / Student } \\
\text { N }(\% \text { in column })\end{array}$ & $\begin{array}{l}\text { Housewife } \\
\text { N } \% \text { in column })\end{array}$ & $\begin{array}{l}\text { Civil servant } \\
\text { N } \% \text { in column })\end{array}$ & $\begin{array}{l}\text { Informal sector } \\
\text { N }(\% \text { in column })\end{array}$ & P value \\
\hline Spontaneous abortion & $\mathbf{2}(22.22)$ & $\mathbf{9}(\mathbf{6 0})$ & $\mathbf{7}(\mathbf{8 7 . 5})$ & $\mathbf{5 9}(\mathbf{6 2 . 7 7 )}$ & $\mathbf{0 . 0 1}$ \\
\hline Induced abortion & $\mathbf{7 ( 7 7 . 7 8 )}$ & $\mathbf{6}(\mathbf{4 0})$ & $\mathbf{1 ( 1 2 . 5 )}$ & $\mathbf{3 5}(\mathbf{3 7 . 2 3})$ & $\mathbf{0 . 0 1}$ \\
\hline TOTAL & $\mathbf{9}(\mathbf{1 0 0})$ & $\mathbf{1 5}(\mathbf{1 0 0})$ & $\mathbf{8}(\mathbf{1 0 0})$ & $\mathbf{9 4}(\mathbf{1 0 0})$ & $\mathbf{0 . 0 1}$ \\
\hline
\end{tabular}

\section{Gesture and type of abortion}

Induced abortion is more frequent in primigravidae $73.68 \%$ and spontaneous abortion in multigestant $87.18 \%$. (Table-2)

Table-2: Type of abortion in relation to pregnancy

\begin{tabular}{|l|l|l|l|l|}
\hline & $\begin{array}{l}\text { Primigeste N (\% en } \\
\text { Colonne) }\end{array}$ & $\begin{array}{l}\text { Paucigeste N (\% en } \\
\text { Colonne) }\end{array}$ & $\begin{array}{l}\text { Multigeste N } \\
\text { en Colonne) }\end{array}$ & P valeur \\
\hline $\begin{array}{l}\text { Spontaneous } \\
\text { abortion }\end{array}$ & $10(26.32)$ & $33(67.35)$ & $34(87.18)$ & 0.03 \\
\hline Induced abortion & $28(73.68)$ & $16(32.65)$ & $5(12.82)$ & 0.03 \\
\hline TOTAL & $38(100)$ & $49(100)$ & $39(100)$ & 0.03 \\
\hline
\end{tabular}

\section{Clinical Data}

In $58 \%$ of cases, our patients were referred. They were in good general condition in $82 \%$ of cases. We counted 107 pregnancies or $84 \%$ of which gestational age was less than or equal to 12 weeks against 19 pregnancies or $16 \%$ of which gestational was between 12 and 14 weeks.

The reason for consultation was metrorrhagia in $74 \%$ of cases, pelvic pain in $14 \%$, and incomplete abortion in $12 \%$.

\section{Support}

Local anesthesia coupled with verbacaïne was used for all of our patients. The use of injectable analgesics before and after aspiration was systematic. Red blood cells were prescribed in $13.5 \%$ of cases, fresh frozen plasma in $4.8 \%$ of cases and antianemics in $90.48 \%$ of cases. All of our women (100\%) had fluids, antibiotics, analgesics and oxytocin. They have all benefited from psychological care. Four (04) patients presented with complications, including three cases (03) of hemorrhage and one case (01) of uterine perforation. Our patients had not adopted a contraceptive method after counseling in $64.29 \%$. In contrast, $22.22 \%$ of them opted for the pills.

\section{DISCUSSION}

The frequency of abortions was $6.18 \%$. Of these, $27.39 \%$ were incomplete abortions and were managed by MIUA. Spontaneous abortions accounted for $61 \%$. Our patients were admitted in $58 \%$ of cases. For Ajavon et al., in Togo in 2018 [12], the frequency of abortions was $6.9 \%$. They came on their own (74.1\%) and admitted for incomplete abortion in $86 \%$. As for Nassira et al., in 2011 in Paquistan [13], incomplete abortions represented $42.45 \%$. In fact, the metrorrhagia and pelvic pain that accompany incomplete abortions prompt patients to consult very early as soon as the first signs appear. This low rate of incomplete abortion supported by MVA, found in our study, is due to the fact that performing MVA requires compliance with certain conditions including the age of pregnancy (84\% of cases, 1 gestational age was less than or equal to 12 weeks and in $16 \%$ gestational was between 12 and 14 weeks).

The average age of our patients is 27 years old. Our results are similar to those of Nassira et al., [13], where the mean age was 27.3 years. This can be explained by the fact that it is the period of full fertility and that sexual activity is very high in this age group.

Induced abortion is more frequent among primigravidae $73.68 \%$ and also among pupils and students $77.78 \%$, while spontaneous abortion was the prerogative of multigestes $87.18 \%$ and also of patient civil servants $87.5 \%$. This can be explained by the fact that at this time of life, most pregnancies are unwanted in primigravidae who are also in search of their future. The sexual act is much more oriented towards a sensual goal than of reproduction. Also, these groups are vulnerable, due to the fact that sexual relations are often occasional, contraception is rarely used, and knowledge is also insufficient.

Consequently, their ability to protect themselves is limited, which exposes them to a higher risk of unwanted pregnancies [14], abortions and sexually transmitted infections including HIV / AIDS. In 81 cases $(64.29 \%)$, our patients had not adopted a contraceptive method after counseling. In contrast, 
$22.22 \%$ of them opted for the pills. For Ajavon et al., [12], 81 patients or $43.8 \%$ had chosen a contraceptive method, including pills in $53.1 \%$. Indeed, despite the pre, per and post MIA counseling, our patients were mostly very young and nulliparous (48\%), and during our study, there were many more cases of spontaneous abortion than induced abortion; therefore, these are women who probably had a desire for pregnancy. So talking to them about contraception is much more difficult to accept right now, even though the uterus needs to be put to rest a little. In view of the circumstances, whether it is a desired pregnancy or not, abortion is always a trauma for the woman. In this sense, all of the patients received psychological support from the psychologist in the department

In our study, the use of solutions, antibiotics, analgesics, syntocinon was systematic, the red blood cell pellet was prescribed in $13.5 \%$ of cases and fresh frozen plasma in $4.8 \%$ of cases and anti-anemic agents in $90.48 \%$ of cases. In the study by Tadele et al in Botsoana in 2018 [15], all patients were put on antibiotics. Blood products were used in $9.5 \%$ of patients. Indeed, WHO recommends the universal use of a single dose of antibiotic prophylaxis for all women who have had an abortion induced by surgery, regardless of the risk of developing pelvic inflammatory disease [16]. Regarding the use of antibiotics in incomplete abortion, the evidence for the universal use of prophylactic antibiotics is insufficient to date [17]. Also, the routine use of antibiotics could be influenced by the fear of postabortion sepsis, as the conditions and environment of the pre-admission abortion are often not fully known. This treatment protocol in our study allowed a good clinical evolution in our patients with an absence of complications in the post abortion.

Three pain control procedures were used in our study namely verbacaine, which is always associated with paracervical anesthesia and the use of injectable analgesics before and after aspiration was systematic. Nasira et al., [13], used paracervical anesthesia in $60.3 \%$. For Dodge et al in 2017 [17], aspiration was done under local anesthesia in $34.8 \%$. Indeed, during MVA, pain control is a criterion for evaluating the quality of postabortion care. It allows an intervention in good conditions of safety and comfort for the patient. Nowadays we tend more and more towards painless care in medicine.

Three point seventeen percent of our patients, $3.17 \%$ developed complications. Our results are lower than those of Tadele et al., [15], who had 22.2\% of serious or moderate complications in his patients. The uterine perforation recorded in our study was not due to MVA but rather a patient who was admitted with the notion of endo-uterine maneuvers and whose perforation was observed during MVA The clinical course was been favorable. After manual intrauterine aspiration, return home is immediate; the first post- abortion check-up is done one week after the MIUA. This first check makes it possible to verify once again the uterine emptiness on ultrasound, it also offers a second chance for the choice of a contraceptive method.

\section{CONCLUSION}

Abortions, whether spontaneous or induced, constitute a public health problem and therefore require adequate management. The availability and simplicity of the MIUA technique are definite advantages. Complications are rarely found. What makes this method, a method of choice that we strongly recommend in the management of abortions. Particular emphasis should be placed on post-abortion contraception.

\section{REFERENCES}

1. World Health Organization (WHO). (2013). Safe abortion: technical and policy guidelines for health systems, 2nd edition, Geneva, WHO, 146.

2. Okonofua, F. E., Hammed, A., Abass, T., Mairiga, A. G., Mohammed, A. B., Adewale, A., \& Garba, D. (2011). Private medical providers' knowledge and practices concerning medical abortion in Nigeria. Studies in Family Planning, 42(1), 41-50.

3. Prata, N., Bell, S., \& Gessessew, A. (2013). Comprehensive abortion care: evidence of improvements in hospital-level indicators in Tigray, Ethiopia. BMJ open, 3(7):e002873.

4. World Health Organization. (2011). Unsafe abortion: global and regional estimates of incidence of unsafe abortion and associated mortality in 2008. Geneva, Switzerland: WHO.

5. Statistical Information Research Studies Division. (2013). Main Health Indicators (2012). Lomé: Republic of Togo. According to: http://www.sante.gouv.tg/index.php?option=com_ docman \&task=cat_view $\&$ gid $=5 \&$ Itemid $=3$

6. Sedgh, G., Henshaw, S., Singh, S., Åhman, E., \& Shah, I. H. (2007). Induced abortion: estimated rates and trends worldwide. The Lancet, 370(9595), 1338-1345.

7. Haddad, L. B., \& Nour, N. M. (2009). Unsafe abortion: unnecessary maternal mortality. Reviews in obstetrics and gynecology, 2(2), 122.

8. Lukman, H. Y., \& Pogharian, D. (1996). Management of incomplete abortion with manual vacuum aspiration in comparison to sharp metallic curette in an Ethiopian setting. East African medical journal, 73(9), 598-603.

9. Hemlin, J., \& Möller, B. (2001). Manual vacuum aspiration, a safe and effective alternative in early pregnancy termination. Acta obstetricia et gynecologica Scandinavica, 80(6), 563-567.

10. Ansari, R., Rathore, S., \& Mustafa, B. (2014). Manual Vacuum Aspiration: A Safe and Effective Alternative for the Surgical Management of Early Pregnancy Loss. Annals of Abbasi Shaheed 


\section{Hospital \& Karachi Medical \& Dental} College, 19(1).

11. Katherine, L., Turner, L. S., \& Heather, M. M. I. (2016). Conclusions of the situational analysis: Needs and opportunities for comprehensive care management abortion in French-speaking West Africa.

12. Ajavon, D. R. D., Ketevi A., Tougma U. N., Douaguibe, B., Logbo-Akey, K. E., Bassowa, A., Kola, A., Houzou, P., Fiagnon, K., Aboubakari, A. S., \& Akpadza, K. (2018). Management of incomplete abortions in the first trimester at the Regional Hospital Center by Kara. AJOL, 20(2).

13. Nasira, T., Ghazala, M., Saba, F., \& Mohsina, S. (2011). Manual vacuum aspiration: a safe and cost-effective substitute of Electric vacuum aspiration for the surgical management of early pregnancy loss. Maternal and Child Health Center, Unit-I, Pakistan Institute of Medical Sciences, Islamabad. 61(2).

14. Sebti, M., Courbage, Y., Festy, P., \& KursacSouali, A. C. (2009). Maghreb, Morocco,
Marrakech: Demographic convergence, socioeconomic diversity (1). Population \& Societies, (459), 1-4.

15. Melese, T., Habte, D., Tsima, B. M., Mogobe, K. D., \& Nassali, M. N. (2018). Management of post abortion complications in Botswana-The need for a standardized approach. Plos one, 13(2), e0192438.

16. WHO. (2012). Safe abortion: technical and policy guidance for health systems Second edition; second Edition.

17. May, W., Gülmezoglu, A. M., \& Ba- Thike, K. (2007). Antibiotics for incomplete abortion. Cochrane Database of Systematic Reviews, (4).

18. Dodge, L. E., Hofler, L. G., Hacker, M. R., \& Haider, S. (2017). Patient satisfaction and wait times following outpatient manual vacuum aspiration compared to electric vacuum aspiration in the operating room: a cross-sectional study. Contraception and reproductive medicine, 2(1), 18. 